Article

\title{
Post-Hype Uses of Drones in News Reporting: Revealing the Site and Presenting Scope
}

\author{
Jonas Harvard \\ Department of Media and Communication Science, Mid Sweden University, 85170 Sundsvall, Sweden; \\ E-Mail: jonas.harvard@miun.se
}

Submitted: 28 April 2020 | Accepted: 8 June 2020 | Published: 27 July 2020

\begin{abstract}
Camera-equipped drones have emerged as an increasingly commonplace tool for media to acquire aerial imagery. Previous research has mainly focused on the innovative aspects and creative potential of the technology. This article argues that early optimistic projections reflected a novelty effect, typical of a culturally embedded idea that new and better technologies continuously replace older ones. Using a historical theory which distinguishes techno-optimistic innovation discourse from actual observations of technology in use, photojournalists were interviewed on the role of drones in news reporting. The results show that the practitioners historicise drones, relating them to previous aerial technologies, and they reflect on current and future uses of drones in journalism based on a notion of phases, where early hype gives way to subsequent drone fatigue. Drones are seen by many as a more convenient tool to do things that journalism has done before, but the convenience increases the use of aerial imagery. The results also show that, although photojournalists see a wide range of potential uses, there are also limitations, including the ideals of the invisible observer, safety concerns, and the perils of over-aesthetic imagery. The post-hype uses of drone photography were summarized in two categories: (a) revealing the site, establishing 'this happened here' and (b) presenting scope, or showing how vast or large something is.
\end{abstract}

\section{Keywords}

drone journalism; drone use; drones; history of technology; media technology; photojournalism; unmanned aerial vehicles

\section{Issue}

This article is part of the issue "Journalism from Above: Drones, the Media, and the Transformation of Journalistic Practice" edited by Jonas Harvard (Mid Sweden University, Sweden), Mats Hyvönen (Uppsala University, Sweden) and Ingela Wadbring (Mid Sweden University, Sweden).

(C) 2020 by the author; licensee Cogitatio (Lisbon, Portugal). This article is licensed under a Creative Commons Attribution 4.0 International License (CC BY).

\section{Introduction}

Journalism research has often applied innovation theory and ideas of 'disruption' to map and better understand the adoption of technology in media organisations and by journalists. This has been particularly true for research on drones and journalism (Belair-Gagnon, Owen, \& Holton, 2017; Ferguson \& Greer, 2019; Gynnild \& Uskali, 2018). Innovation theory tends to come with a baggage of techno-optimism, implying that innovations replace or supersede previous technology, and journalism research has been criticised for being too technology centred (Zelizer, 2019).

As camera-equipped drones have quickly gone from a novelty to a multi-billion-dollar industry involving con- sumers as well as journalists and professionals in many different areas, a larger historical perspective on the current situation is necessary. There may also be signs that the drone industry has seen its golden years; Bloomberg (2019) recently headlined that the "drone bubble" had burst and many drone companies were going bankrupt. Adams observed that "drone fatigue" was increasing in journalism and noted industry comments that drones were a "passing fad" (Adams, 2019, pp. 1-2).

Through interviews with photojournalists and image editors, the current article analyses how drones are historically situated by practitioners in news organisations and how the interaction with previous technologies and professional values, as well as societal factors, shapes how photojournalists see the current potentials and limi- 
tations of using drones in newsgathering. This article fills an empirical gap, in that data from practitioners have been scarce, but it also contributes to the discussion of breaks versus continuity in the history of emerging media technologies.

The article also adds a perspective from the Swedish media landscape. In the Swedish media system commercial news media coexist with a public service broadcasting system for television and radio (Weibull, Wadbring, \& Ohlsson, 2018). Early Swedish legislation categorized drones as a form of camera surveillance but allowed journalistic uses on condition that a special permit was obtained. In 2016 a court order significantly limited the range of allowed uses and for a period journalistic drone photography was effectively illegal. A revision in 2017 eased restrictions, and since 2018 no permit is needed to fly drones weighing less than 7 kilos, as long as flights follow certain rules and no-fly zones are avoided (Transportstyrelsen, 2017).

Historians have shown that the progression in the life of a new technology-from introduction and visionary statements from proponents, to the subsequent phase of sobering up, potential disappointment and long-term co-existence with other technologies-is a repeating pattern. Similar cycles have been observed for the introduction of telegraphy, telephony, wireless broadcasts, television and other technological advancements (Marvin, 1988; Rhodes, 2012). An important part of the initial phase is the existence of enthusiastic media coverage of the new technology. In the case of drone journalism, the contrast between how the media has covered drones as a news item and how they are actually employing drones in newsrooms has been observed (Vobič, 2020).

This shift from viewing technological changes in the media sector as radical transitions where new technologies replace previous ones, to envisioning a process where new technology is added to an existing set of technologies and practices and its complementary benefits absorbed, implies a different temporal focus. Instead of seeking to explain rapid change, we are concerned with processes taking place over a longer period. From a longer historical perspective, the potentially disruptive impact of new journalistic technologies is often moderated by the contexts in which they are applied, and technology is adapted to already existing routines and values by news workers (Fenton, 2010; Singer, 2005).

Within an overall framework of this type of layered journalistic technological development, cameraequipped drones constitute a special type of journalistic technology that is concerned with the production of visuals. From its inception, visual journalism has held a special position as truth-teller, with photography having a strong impact on the documentary legitimacy of news stories (Brennen, 2009; Hall, 1973; Ray, 2020). Cameraequipped drones further constitute a very particular kind of visual technology - the aerial view. Whereas the truthclaims of visual representation from the ground can, in theory, be checked by a member of the public, aerial im- agery represents a form of seeing not available to the everyday observer and "a culturally specific way of seeing, or visuality" (Mangold \& Goehring, 2019, p. 25).

Implicit in the intersection between drone technology and journalism are both the long lineage of aerial imaging technologies and the tension between the aerial as neutral and truthful and something which gives a previously impossible visual experience.

\section{Theory}

In a timely critique of innovation-centred histories of technology, David Edgerton (1999) has placed innovation discourse in a larger societal context and provided a historically grounded approach for analysis. A key point is that innovation discourse in itself is an important part of modern society, which makes objects that can be linked to notions of the 'new' or 'groundbreaking' inherently important and interesting. Edgerton argues that rather than adoption, which he suggests can be rather swift and easily traceable, analysis of technological changes should focus on the extent and forms of the uses of technology. Histories of actual use over time often tell a different spatial and geographic story than the history of how a particular technology first came to be adopted by the public, institutions, or professionals. The perspective of use often reveals that older technologies continue to be of great importance, long after the time when they were deemed outdated and considered to have been 'replaced' (Edgerton, 1999).

Taking this critical approach further, Müller and Tworek (2016) have proposed the idea of 'imagined use' as a fruitful category of analysis. In an innovation-centric society such as ours, optimistic projections of the potential of new technologies into the future can often serve to guide and influence practical choices in the present. Their analysis highlights the importance of the contents of what can be called the 'hype' phase.

For journalism research, the digital revolution has meant the emergence of lively research streams, but also an increased focus on the tools used to produce journalism. Recently, Katie Day Good (2017) has pointed out the tendency of journalism research to focus solely on technology, and she reiterates warnings about seeing journalistic transformation as a one-way street forward, where new forms and technologies automatically replace old ones. In periods of technological change, she reminds us, different media forms interact in "unsettled" ways as new and old technologies recombine and interact, leaving revised roles for long-existing technologies.

In a broader critique of the tendency to define journalism in relation to technology, as in digital journalism, Zelizer claims that starting with technology obscures not only that changes in journalism are incremental, but also that there sometimes are detrimental outcomes of change. Focusing on technology also fails to distinguish what stays stable in journalism beyond technological change (Zelizer, 2019). 
In the current environment, many scholars have observed that journalists are increasingly expected to master multiple production technologies and become multiskilled (Nygren, 2014). Örnebring (2010) has suggested that this constitutes a recent example of the longer historical development of journalistic labour, where decisions by employers to invest in technology lead to changes that impact everyday journalistic work such as newsgathering. How journalists choose to interact with new technologies (and their newness) in everyday use, thus also reflects how journalists define and re-define their own agency in relation to evolving technological demands.

\section{From Game Changer to Everyday Journalistic Tool}

When assessing research on the role of drones in journalism, one encounters several points of view which seem to contradict each other. Some early research in the field has called media use of drones a "disruptive innovation" (Gynnild, 2014) which embodied journalistic eyewitness ideals (Zelizer, 2007), and a "global game changer" in journalism (Gynnild \& Uskali, 2018). A study on how early adopters experimented with drones concluded that they dwelled on the fringes of accepted journalistic practice, but implicitly affected their respective organisations, providing an example of innovation adoption from within (Belair-Gagnon et al., 2017). In contrast to such accounts of creative development, however, others have shown the relative lack of actual drone use by news organisations, citing not only legal concerns and safety issues, but also the weak connection to newsworthiness (Barrero, 2018). A survey of local TV stations in the United States indicated that, although half of the stations owned drones, these were only used moderately, and the study found no evidence that drones were used because of their importance for news stories (Ferguson \& Greer, 2019). One critical overview agreed that drones could contribute to newsgathering where "geographically unconstrained coverage" was of interest, such as natural disasters, public unrest or conflicts, but pointed to the limited uses of drones in practice by news organizations (Ntalakas, Dimoulas, Kalliris, \& Veglis, 2017, p. 193). John Pavlik, in a study of immersive journalism, found a number of production related reasons that drones would become increasingly important for providing visual context, but emphasized that they should be seen in relation to a continued importance of on-the-ground reporting (Pavlik, 2015).

It thus seems that, although there is a broad range of research that places drones as a central component in a major transformation of journalism towards more immersive and audience-oriented practices, there are indications that the actual use of drones in journalistic practice is more limited. Against this background, the purpose of the current article is to place drones in a larger historical perspective and, based on interviews with practitioners, analyse how they see the potential and limitations of drone journalism.

\section{Method}

To shed light on how practitioners see drones in relation to past, current, and future uses of aerial imagery in journalism, in-depth interviews were performed with 19 Swedish photojournalists involved in using drones for media production. Interviews were suitable since the views of practitioners regarding drone uses were the focus (Remenyi, 2011). The interviewees were selected through a combination of strategic samples, by approaching photographers at Swedish newspapers who were known to have used drones, and then through a snowball method enrolling their aid in finding further subjects. An overview of the interview subjects is given in Table 1. In relation to images and journalism, the breadth of working roles among those interviewed $(N=19)$ mirrored the hybrid nature of image production in the current media landscape. Out of those interviewed, 15 worked directly as producers of content, still images, or video for newspapers or television. Four informants worked for newspapers or news organisations, either as head photo editors $(\mathrm{N}=2)$ or editors/producers of online Web TV $(N=2)$. Those not working directly in the field had backgrounds as photographers or photojournalists and were involved in decision-making on the use of drones in everyday newsgathering. A freelance position was common, and around half of those interviewed $(\mathrm{N}=9)$ worked on a freelance basis. Whereas many freelancers had a steady working relationship with a particular employer, four of the interview subjects worked as free agents.

The interviews followed a semi-structured approach, where open-ended questions were combined with a set of questions where subjects were asked to comment more specifically on the value or appropriateness of using drones in different types of settings. Follow-up questions were used to clarify statements or to encourage further reflection on the themes discussed. The format enabled a certain amount of dialogic interaction, while still adhering to a pre-determined thematic structure (Kvale, 2006).

The interviews were carried out via telephone or video conferencing software during the summer of 2018 and took a total of 11 hours, with on average 35 minutes per interview. The audio material was subsequently transcribed and resulted in 354 pages of text. The transcripts were analysed thematically using a combination of top down and ground up analysis to both identify patterns in the responses to the interview questions and identify spontaneously emerging themes, and to investigate these themes systematically (Dearnley, 2005).

The titles of those interviewed were self-selected during the interviews as part of an introductory question. Although only two mentioned the term photojournalist, the majority of those interviewed had working roles which would fit the general definition of a photojournalist as someone who produces visual media content with a journalistic purpose, but who may also write, edit, or do journalistic research (Ferrucci, Taylor, \& Alaimo, 2020). The selection is also in line with the broader definition of 
Table 1. List of photojournalists interviewed in the study.

\begin{tabular}{llll}
\hline Informant code & Title & Freelance & Workplace \\
\hline PH1 & Photographer & Yes & National television \\
PH2 & Video photographer & Yes & National daily newspaper \\
PH3 & Photographer & Yes & \\
PH4 & Photographer and journalist & & Local daily newspaper \\
PH5 & Photographer & National daily newspaper \\
PH6 & Photographer & Yes & National daily newspaper \\
PH7 & Photographer & & National daily newspaper \\
PH8 & Photojournalist & & National daily newspaper \\
PH9 & Photographer & Yes & National tabloid newspaper \\
PH10 & Photographer & Yes & National television \\
PH11 & Photographer & Yes & National tabloid newspaper \\
PH12 & Photojournalist & Yes & Local daily newspaper \\
PH13 & Photographer & & Local daily newspaper \\
PH14 & Web TV editor & & \\
PH15 & Video reporter & Yes & Local daily newspaper \\
PH16 & Photographer and video producer & & National daily newspaper \\
PH17 & Live TV producer & & News agency \\
PH18 & Head photo editor & &
\end{tabular}

Adams (2019, p. 16) of drone journalism, which includes "journalism in which a drone is used... but also the relevant scripting and editing." In sum, this selection of informants provides a broad sample of how drones have been used, seen, and integrated in the Swedish media landscape, with an emphasis on newspapers with a national scope.

\section{Results}

\subsection{Comparisons to Historical Aerial Technologies}

The advent of drone aerial imaging was placed in a longer historical context by many of those interviewed. They underlined that the use of images taken from above was nothing new, and many different ways of achieving shots from above had been used over time. They described a variety of technologies, both using equipment like "fishing rods" or masts to get the camera higher (PH18), but also basic strategies like climbing up to high spots or setting up in a house near an event (PH15). One interviewee referred to drones as a continuation of renting a "big skylift" (PH13). Another recounted spending many years "mounting cameras," in high places "just to get a shot." From that perspective, drones simplified things (PH8).

The main historical comparison was to that of using motorised vehicles. Many related to well-established practices of hiring helicopters ( $\mathrm{PH} 1,2,3,4,5,7,8,10,15$, $16,17,18,19)$ or airplanes (PH1, 4, 5, 15, 16, 17, 19). Thus it was not the aerial perspective itself that was novel, but that it had become more easily accessible:

If you take this example with a train accident or Tour de France, those types of images have always existed as a part of the journalistic image, but then they were often taken with a helicopter, so it is not that you have never seen aerial photos before as a readeryou have seen them....So the type of image has always existed, but I can imagine that it has gotten a lot more common. (PH19)

Hiring a helicopter was previously something only larger newspapers or media institutions could afford. Drones had thus broadened access to the production of aerial imagery. Although drones had made aerial photography more accessible, using a helicopter was still preferred on some occasions, in part because they were seen as a controlled part of the airspace: One commented that when covering a highway traffic jam, it would "still be easier to fly a helicopter" (PH18). As they situated drones in this longer historical context, seasoned photojournalists described drones as "just another tool" - just as they may use a wide-angle lens, they could choose to use a drone, as an "equipment detail" (PH1). It was one of many technologies they used as visual journalists, a tool in the toolbox, "just like all other tools" (PH9).

When photojournalists discussed the possibilities and limitations of drones for their craft and media content, their reflections did not constitute reactions to an entirely new media form, but rather ways of relating to a recent variation in a long-standing component of media reporting.

\subsection{From Novelty Enthusiasm to Drone Fatigue}

In their photojournalistic practice, the interview subjects had seen fads come and go. To them, it was natural that a new technology would initially raise interest. Sometimes 
it was "the delight of something new" that made an image interesting (PH8). Several concluded that there had indeed been a phase where everything shot by drone was seen as interesting in itself: "It almost didn't have to be a news event, it was enough to show how a place or a society looked from above to raise a lot of interest." Now the "drone effect, this idea that the unique is that it is a drone shot" had worn off, which meant that there was not "just the same hype around it anymore" (PH14).

The interview subjects drew historical comparisons to other popular formats whose popularity had faded. When a new type of flash appeared or underwater camera houses became common (PH3), or when cameras started to be mounted on top of goalposts ( $\mathrm{PH} 8$ ), then all of a sudden there had been a flood of these types of images, which had quickly led to diminished interest. This was also becoming true of drones: "And I would say that we currently have too much drone photography in journalism - It is getting old" (PH7). One saw a future of more restricted use:

It will definitely play a role, but I don't think it will have the same leading role that it has had....That it can be a thing for a news site to just say 'here we have the drone perspective from this event' for example....I think both producers and consumers will be quite fed up with that. (PH11)

Just as the initial interest in newspapers that produced web TV waned when everyone could have their own channel and broadcast on social media, the popularisation of drones created drone fatigue. Once everyone could own a drone, it was not "as special anymore," and as more non-professionals acquired drones, the more it became trite and seen as a mannerism (PH15). Nowadays, some said, drones were found in "every other home" and so many were using drones that it did not merit special attention. It took something more spectacular for people to light up, and the audience was quickly becoming blasé: "Oh, okay, you flew a drone...that did not make it more interesting" (PH17). Media outlets had to be careful "not to make everything a helicopter or drone session. Then it really loses its purpose" (PH5).

In contrast to the phase when a drone photo or video was interesting just because it was shot with a drone, the goal once usage had matured was to make technology invisible. This was formulated succinctly by one photojournalist who said the goal was not to get a viewer to react: "what a great drone shot" but have them react "what a great shot" (PH8).

\subsection{Limiters for Broader Use}

In addition to expressing that journalism had become over-saturated with drone-generated aerial footage, the interviewed, based on their professional experience, also saw a number of limiting factors that in many ways hamstrung the future creative use of drones. Although legal and ethical issues were mentioned, they did not constitute the main limitations.

\subsubsection{The Ideal of the Invisible Observer}

One limiter was that drones were anything but discreet and their intrusive presence clashed with the documentary idea of the photographer as an invisible observer. The principle that as a photographer or filmmaker one should be "noticed as little as possible" (PH1) showed up in many different forms during the interviews. One contentious issue was sound. The sharp noise of drone propellers drew attention in an unwanted way (PH9, 10). Others pointed out how clearly visible the drone was, as a dark object against the bright sky "and people notice it and are bothered by it" (PH15). Several interviewees recounted how the use of drones had interfered with their coverage of news stories. One photojournalist had been shooting a youth football tournament. Once he started the drone, the kids stopped playing and instead came to watch his operation of the drone (PH5). Another stated that drones acted as an integrity trigger: "What shall I say, the presence of a drone can lead to a type of provocation.... I am not there to provoke; I am there to document. So, there we need to be careful" (PH14).

Thus, although drones provided easier access to a perspective from above, their presence at the same time interfered with other valued aspects of the photojournalistic work.

\subsubsection{Safety and Collaboration with Rescue Services}

Safety was a concern mentioned by nearly all the interviewees. Not only could propellers create deep cuts, but getting hit by a crashing drone could be lethal. It would be as though a rock of several kilos dropped on one's head (PH8). There was also a reputation risk inherent in safety concerns. If a major news organisation crashed a drone while reporting, the crash would in itself become a piece of news, an "accident within the accident" (PH3).

Flying near crowds was something that worried many interviewees. That was inherently risky and should be avoided (PH4, 5, 10, 12, 16, 18, 19). Some said they covered crowds, but never flew right over, but remained to the side (PH5). The issue of crowds illustrates the duality of using drones in journalism. Visually reporting the size or movement of a crowd was a typical type of imagery that suited the drone well, but was in practice limited by safety issues. Maintaining good relationships with the police and rescue personnel was another issue. Drones could seldom be used at active crime scenes or where accidents were ongoing, due to the risk of interfering with the work of these personnel ( $\mathrm{PH} 2,3,4,5,8,11,15,16)$.

\subsubsection{The Allure and Peril of Aesthetics and Abstraction}

When it first emerged, the quality of drone imagery had stunned many. This was both an asset and a risk. Visually 
appealing photography or video was not seen as bad in itself, but the aesthetic side should not be allowed to take over. Filmic imagery was not was required in classic news reporting, where it could detract from legitimacy. The important thing was to tell a straight story rather than have good-looking angles (PH17). It was said that drone footage would never come into play for ordinary coverage of breaking news, but rather in more long-term journalism which aimed at "educating people" (PH4). That is, it was not in regular news stories, but on occasions where filmic quality was important, that drones would be used (PH18). Some were positive towards the "Hollywood" look though; in particular it was seen as interesting to "highlight" in a Hollywood manner something that was not in itself inherently cinematic (PH4).

Drone shots sometimes tended toward the map-like, and some early abstract "guess-where-this-was-taken" types of drone stories had been published. But still photos from drones quickly started to look like "Google maps" all the time, which was boring and of little interest (PH15). Many expressed disdain for abstract graphical drone shots, saying they were "allergic" to map-like pictures (PH3). This also resonated with the idea of getting close to people as an important part of quality journalism. Some of the best photos came from walking around and meeting people, face to face, and using a drone took the photojournalist away from that (PH7).

In sum, the intrusiveness of drones in use, safety risks, and the risk of overly aesthetic or abstract images were three factors limiting the use of drones. There were, however, broad categories of journalistic drone use, on which the interviewees in general agreed.

\subsection{Revealing the Site}

An appropriate circumstance for using drones was when revealing a site to the audience, showing where something happened, but also explaining relationships between objects on the site. In the language of the interviewees, this was most commonly referred to as providing an "overview" (PH16). As an extension of this overview, drones were also used to create explanatory graphics (PH9). Such graphics could, in more advanced cases, involve using the drone for photogrammetry, creating 3D models which could then be adapted to explain a particular situation (PH4, PH18). In such examples, drones provided raw material which was then further refined. In relation to the results found by Belair-Gagnon et al. (2017), the use of drones to create a basis for graphics presented by participants in this study seemed less a pioneering work and more integrated in the production chain.

The concrete examples of situations where drones would be suitable were often related to infrastructure. Drones were perfect if you wanted to shoot a "housing complex" which was hard to cover from the ground (PH19). Using drones to cover infrastructure, such as roads or houses, gave a better overview and showed "where it is in relation to other known landmarks" (PH15).
One suggested:

Say that a whole bridge is about to be taken down, and a new one is built 50 metres away. It is perfect to use a drone for that, just to tell what it actually looks like, instead of drawing or taking bad pictures from the ground. (PH17)

Drones could also be used to illustrate relationships between objects on a site (PH19). Using drones to establish spatial relations could be seen in crime coverage. Using the example of a murder story, a drone could show a road and then the bushes along the road, and the drone could show how close to the road the body had been, telling the viewer "here the body was found" (PH11). Such presentations were formulated to give "a completely different overview" (PH4). This overview could "explain" things much better "than seeing things from the ground," again showing "this happened here" (PH6). When filming a building on fire, a drone could show where exactly it was burning and how (PH14).

Another way of using drones to present a site was to create atmosphere (PH9). Many video news segments begin with an overview image, and if that image could also set a mood, it was considered an advantage (PH3). Sometimes mood-setting illustrations of site played on stereotypes. One occasion of using a drone to illustrate a suburb involved a shot of the location from above showing the subway passing by; the photojournalist reflected: "It is so iconic" (PH12).

\subsection{Presenting Scope}

A second category seen as relatively unproblematic was presenting scope. Here the contribution of the drone could be to show how big something was or how far something reached, sometimes by placing a smaller object in the foreground. Many of the examples involved information that something was the biggest of its kind. One photographer used a drone to present a retirement community which was "the world's biggest" (PH13). If they could be covered safely, public manifestations-not everyday demonstrations, but "something large or a really large demonstration" - would be better illustrated with a drone (PH14). Another example was using a drone to cover the vastness of a giant refugee camp, where over a million people lived in a clearly defined area (PH6). A more everyday example that still illustrates the importance of size involved filming an explosion at a construction site, which was "the biggest" the company had ever done and involved hundreds of kilos of dynamite (PH14).

Drones could make the contrast between big and small or far and near more striking, such as when shooting a lone runner crossing an open field. From the ground "you can't tell how big the area is or how hard it is. On such an occasion it can be very revealing to come up from a higher angle, to show what a giant marshland someone is running through" (PH8). Another example was if 
you were travelling with a freight ship across the ocean, it would be "obvious" to bring a drone to show "the open water, the lone boat, coming from out there and looking inwards. There it really contributes something" (PH7).

Natural phenomena were considered an obvious area where drones could be used to present scope. Drones were ideal to illustrate "the size of things which are big" and which could not be captured from the ground, such as forest fires (PH9). For natural phenomena, using drones was "spot on" to show "the extension of flooding or a drought" (PH6). In a story about conflicting land claims, a drone would be useful to "provide an overview of the land mass in itself" (PH11).

\section{Conclusion}

This article has analysed how photojournalists position drone camera technologies in relation to existing modes of acquiring images from above and the potentials and shortcomings they see with drone photography. Drones were related historically to an already existing visual genre of aerial imagery and its connected technologies, both helicopters and airplanes, but also to simpler methods such as climbing houses or using high poles. Drones did not represent something entirely new, but facilitated the acquisition of imagery which had been more exclusive. This novelty effect initially gave rise to hype and enthusiasm for the new technology: Drones in themselves held a news value. However, this led to overuse and a reaction against them.

This image of a more reserved attitude among photojournalists contrasts with research exploring the creativity of early adopters (Belair-Gagnon et al., 2017) and other studies which have positioned drones as a disruptive innovation (Ferguson \& Greer, 2019; Gynnild \& Uskali, 2018) The results are more in line with the more critical approaches that have highlighted limiting factors in the actual use of drones (Barrero, 2018; Ntalakas et al., 2017), as well the results of content analysis of drone journalism, which found that in the majority of the cases, drone footage was used to establish context (Adams, 2019).

On a theoretical level, the results illustrate the value of analysing technology in use to get a broader sense of how a new technology affects society (Edgerton, 1999). In actual use, old and new technologies co-exist, and in the case of drones, their incorporation into journalistic practices was facilitated by the pre-existence of a well-established genre of aerial photography. The rapid spread of drones in society over time, paradoxically, decreased the attractiveness of drone imagery among photojournalists. Some still preferred to use helicopters to achieve aerial shots.

The analysis also showed that photojournalists imagined a wide range of potential applications for drone filming and photography, but that safety-as well as problems with intrusiveness and aesthetic ideals-limited several of these application areas. Some of these poten- tial but unfulfilled uses could be understood using the category of imagined use (Müller \& Tworek, 2016) which posits that non-experienced uses can still shape actions. The types of use which were seen as carrying long-term journalistic potential can be summarised into the categories site and scope, where drones are used to establish place and spatial relationships and to communicate size or extension.

The extent to which the photojournalists distanced themselves from the hype around drones can also be interpreted in relation to the issue of journalistic agency and the concept of journalistic labour (Örnebring, 2010). The emphasis that drones were "just a tool" can be seen as way to claim the importance of professional specialist competence, implying that as photojournalists they were not owned by technology, but made independent journalistic judgements of when using drones was suitable, and when it was not.

It should also be acknowledged that the results of the study may have been impacted by the selection of informants. Many worked at well-established media outlets in the Swedish media landscape, and in some cases these had a generous history of using resources to acquire aerial imagery. Such experiences may have led to a less convinced attitude towards the newness factor of drone photography. To other media outlets, with fewer resources, drones could represent a previously unavailable opportunity to get an aerial view. The contrasts to earlier research also likely reflect that the present interviews were conducted at a later point in time, when more mature usage patterns had developed. The early adopters interviewed in earlier research might later come to exhibit signs of drone fatigue.

\section{Acknowledgments}

The author wishes to thank Terje Lindblom for conducting the interviews and the anonymous reviewers for helpful and constructive criticism.

\section{Conflict of Interests}

The author declares no conflict of interests.

\section{References}

Adams, C. (2019). Tinker, tailor, soldier, thief: An investigation into the role of drones in journalism. Digital Journalism, 7(5), 658-677.

Belair-Gagnon, V., Owen, T., \& Holton, A. E. (2017). Unmanned aerial vehicles and journalistic disruption: Perspectives of early professional adopters. Digital Journalism, 5(10), 1226-1239.

Barrero, M. Á. F. (2018). Journalism and drones. Challenges and opportunities of the use of drones in news production. Doxa Comunicación, 26, 35-58.

Bloomberg. (2019, September 1). Drone bubble bursts, wiping out startups and hammering VC firms. 
Industryweek.com. Retrieved from https://www. industryweek.com/technology-and-iiot/article/ 22028168/drone-bubble-bursts-wiping-outstartups-and-hammering-vc-firms

Brennen, B. (2009). Photojournalism: Historical dimensions to contemporary debates. In S. Allen (Ed.), The Routledge companion to news and journalism (pp. 71-81). London: Routledge.

Dearnley, C. (2005). A reflection on the use of semistructured interviews. Nurse Researcher, 13(1), 19-28.

Edgerton, D. (1999). From innovation to use: Ten eclectic theses on the historiography of technology. History and Technology, an International Journal, 16(2), 111-136.

Fenton, N. (2010). News in the digital age. In S. Allen (Ed.), The Routledge companion to news and journalism (pp. 557-567). New York, NY: Routledge.

Ferguson, D. A., \& Greer, C. F. (2019). Assessing the diffusion of drones in local television news. Electronic News, 13(1), 23-33.

Ferrucci, P., Taylor, R., \& Alaimo, K. I. (2020). On the boundaries: Professional photojournalists navigating identity in an age of technological democratization. Digital Journalism, 8(3), 367-385.

Good, K. D. (2017). Listening to pictures: Converging media histories and the multimedia newspaper. Journalism Studies, 18(6), 691-709.

Gynnild, A. (2014). The robot eye witness: Extending visual journalism through drone surveillance. Digital Journalism, 2(3), 334-343.

Gynnild, A., \& Uskali, T. (2018). The first wave of drone journalism: From activist tool to global game changer. In A. Gynnild \& T. Uskali (Eds.), Responsible drone journalism (pp. 15-35). London: Routledge.

Hall, S. (1973). The determinations of news photographs. In S. Cohen \& J. Young (Eds.), The manufacture of news: Deviance, social problems and the mass media (pp. 226-243). London: Constable.

Kvale, S. (2006). Dominance through interviews and dialogues. Qualitative Inquiry, 12(3), 480-500.

Mangold, E. B., \& Goehring, C. (2019). The visual rhetoric of the aerial view: From surveillance to resistance. Quarterly Journal of Speech, 105(1), 25-41.

Marvin, C. (1988). When old technologies were new: Thinking about electric communication in the late nineteenth century. New York, NY: Oxford University Press.

Müller, S. M., \& Tworek, H. J. (2016). Imagined use as a category of analysis: New approaches to the history of technology. History and Technology, 32(2), 105-119.

Ntalakas, A., Dimoulas, C. A., Kalliris, G., \& Veglis, A. (2017). Drone journalism: Generating immersive experiences. Journal of Media Critiques, 3(11), 187-199.

Nygren, G. (2014). Multiskilling in the newsroom: Deskilling or re-skilling of journalistic work? The Journal of Media Innovations, 1(2), 75-96.

Örnebring, H. (2010). Technology and journalism-aslabour: Historical perspectives. Journalism, 11(1), 57-74.

Pavlik, J. V. (2015). Transformation: Examining the implications of emerging technology for journalism, media and society. Athens Journal of Mass Media and Communications, 1(1), 9-24.

Ray, L. J. (2020). Social theory, photography and the visual aesthetic of cultural modernity. Cultural Sociology, 14(3), 139-159.

Remenyi, D. (2011). Field methods for academic research: Interviews, focus groups, and questionnaires in business and management studies. Reading: Academic Publishing International.

Rhodes, R. (Ed.). (2012). Introduction. In Visions of technology: A century of vital debate about machines systems (pp. 1-26). New York, NY: Simon and Schuster.

Singer, J. B. (2005). The political j-blogger: "Normalizing" a new media form to fit old norms and practices. Journalism, 6(2), 173-198.

Transportstyrelsen. (2017). Transportstyrelsens föreskrifter om obemannade luftfartyg [The Swedish Transport Agency regulations regarding unmanned aerial vehicles] (TSFS 2017:110). Norrköping: Swedish Transport Agency.

Vobič, I. (2020). Drone journalism. In T. P. Vos, F. Hanusch, D. Dimitrakopoulou, M. Geertsema-Sligh, \& A. Sehl (Eds.), The international encyclopedia of journalism studies. Hoboken, NJ: Wiley.

Weibull, L., Wadbring, I., \& Ohlsson, J. (2018). Det svenska medielandskapet: Traditionella och sociala medier i samspel och konkurrens [The Swedish media landscape: Traditional and social media in interaction and competition]. Stockholm: Liber.

Zelizer, B. (2007). On "having been there": Eyewitnessing as a journalistic keyword. Critical Studies in Media Communication, 24(5), 408-428.

Zelizer, B. (2019). Why journalism is about more than digital technology. Digital Journalism, 7(3), 343-350.

\section{About the Author}

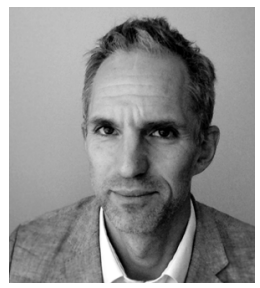

Jonas Harvard is Associate Professor and Researcher in media history at the Department of Media and Communication Science, Mid Sweden University. His research focuses on the current and historical roles of technology in journalism and how strategic communication choices by individuals and institutions have interacted with cultural and political ideas of communication. He has published several articles and book chapters about the history of the electric telegraph and analysed public discourse about political opinion and persuasion in the Nordic countries and the United Kingdom. 